\title{
ENDOPHYTES OF SERAPIAS PARVIFLORA PARL. AND SPIRANTHES SPIRALIS (L.) CHEVALL. (ORCHIDACEAE): DESCRIPTION OF ENDOPHYTES OF S. PARVIFLORA, AND IN VITRO SYMBIOSIS DEVELOPMENT IN S. PARVIFLORA AND SPIRANTHES SPIRALIS
}

\author{
Pier Luigi PACETti and SABine Riess \\ Dipartimento di Scienze Ambientali, Università della Tuscia, I-01100 Viterbo, Italy
}

\begin{abstract}
Endophytes were isolated from Serapias parviflora (Orchidaceae) roots. They are described and partially classified under microscope, after growth on PDA. Two fungi had symbiotic characters: A-Sepa-1, an ascomycete, and B-Sepa-1, a basidiomycete. At the same time, many plants of $S$. parviflora and Spiranthes spiralis were asymbiotically obtained by sterilisation of seeds and sowing on modified Frosch medium. After transplantation to symbiotic medium (modified Basic Oats), they were inoculated with isolated fungi. Serapias parviflora was used as control and S. spi ralis was used to establish specificity between hosts and endophytes. The two fungi were able to induce symbiosis in S. parviflora roots in vitro, while only B-Sepa-1 induced symbiosis in S. spiralis roots in vitro. We conclude that specificity between these fungi and the two orchid species studied in vitro is different, possibly substantiating the hypothesis of a potential and ecological specificity.

RESUMEN. Hongos endófitos fueron aislados de raíces de Serapias parviflora (Orchidaceae). Fueron descritos y clasificados parcialmente bajo el microscopio de luz luego de ser cultivados en PDA. Dos de ellos presentaron características de simbiontes: la Cepa-A-1, un ascomicete, y la Cepa-B-1, un basidiomicete. Al mismo tiempo muchas plantas de S. parviflora y Spiranthes spiralis fueron obtenidas asimbióticamente por esterilización de semillas y cultivo en un medio Frosch modificado. Luego de transplantarlas a un medio simbiótico (Oats modificado), las plantas fueron inoculadas con los hongos aislados. Serapias parviflora fue utilizada como control y $S$. spiralis lo fue para establecer especificidad entre hospederos y endófitos. Los dos hongos fueron capaces de inducir simbiosis in vitro en raíces de $S$. parviflora, mientras que sólo la Cepa-B-1 indujo simbiosis in vitro en raíces de $S$. spiralis. Concluimos que la especificidad in vitro entre estos hongos y las dos especies de orquídeas estudiadas es diferente, posiblemente apoyando la hipótesis de una especificidad ecológica potencial.
\end{abstract}

Key Words: Orchidaceae, Serapias parviflora, Spiranthes spiralis, symbiotic fungi, endophytes, Italy.

Introduction. Orchids need endomycorrhizae to develop: green orchids need fungi for the early developmental stages, while orchids lacking chlorophyll are always completely dependent upon fungi. Endophytes of orchids are always Mitosporic Fungi. Three classes are recognized in this group: Hyphomycetes, Coelomycetes, and Agonomycetes. To the latter class belong sterile fungi that may produce chlamydospores or sclerotia and the genus Rhizoctonia DC., whose members may also produce sclerotia. Most orchid endophytes are ascribed to this group. Only few traits were used to describe this genus (Curtis 1937) but unfortunately they have no taxonomic value since they do not allow discrimination between very similar Rhizoctonia species with very different perfect states. Rambelli (1981) suggested the presence of dolipores or clamp connections as a character to assign a fungus to the basidiomycetes when reproductive structures are absent. Moreover, Riess 
and Scrugli (1987) suggested to classify orchid endophytes in four morphometrical classes: A, B, $\mathrm{C}$, and D. This classification has no taxonomic value, but because fungi are studied when they are into cortical cells, it gives information on fungal ecology. Three ascomycetes strains with Rhizoctonia-like anamorphs were isolated from Pterostylis sp. but no seeds germinated when they were inoculated with these fungi (Warcup 1975). Some tropical orchids have ascomycetes as symbiont (Dreifuss \& Petrini 1981 and 1984); formerly these fungi were described as Ascorhizoctonia Chin S. Yang \& Korf, but since they are saprobe fungi and do not produce sclerotia they can not be ascribed to the genus Rhizoctonia DC. (Andersen 1986). Septum ultrastructure of Leptodontidium orchidicola Sigler \& Currah (Mitosporic Fungi) isolated from tropical orchids reveals that this anamorph is related to ascomycetes in having Woronin bodies near its septum pore.

One of the first questions about the relationship between orchids and endophytes deals with the specificity. Bernard (1909) hypothesised a high level of specificity but such close relationship was soon rejected. Burgeff (1936) proposed that specificity existed between some fungi and ecological host groups, and Curtis (1937) suggested a closer relationship between fungus and habitat. Hadley and Harvais (1967) questioned Curtis' ecological specificity because not all fungi isolated from ripe plants were able to support host seed germination. Further works built up evidence in favour of the absence of specificity (Downie 1959, Hadley 1970). Riess and Scrugli (1987) observed that some orchid species (Ophrys bombyliflora Link. and Ophrys tenthredinifera Willd.) had different endophytes when collected in different sites. They also observed, in the same work, that in Limodorum abortivum (L.) Sw. there were simultaneously two endophytes with different morphological characters. Similar results were obtained from Curtis (1937), Downie (1943), Talbot and Warcup (1967), and Harley (1969). Masuhara and Katsuya (1989, 1994), by studying Spiranthes sinensis (Persoon) Ames var. amoena (M. Bieberstein) Hara, suggested two kinds of specificity: 1) "ecological specificity", i.e. when pelotons are into root cortical cells or into the protocorms in nature (in situ); and 2) "potential specificity", i.e. associations between orchids and fungi in other conditions, both in vitro or ex vitro. Masuhara and others (1993) observed ecological specificity only in some fungi with potential specificity. For example, Microtis parviflora $\mathrm{R}$. Br. (Orchidaceae) has a narrow ecological specificity in the field, while showing a broad potential specificity in vitro. The factors that contribute to ecological specificity could be fungal growth and survival in the soil, which are influenced by environmental factors, or fungal density in the field (Masuhara and others 1995). Milligan and Williams (1988; in Masuhara \& Katsuya 1995) suggested that differences between ecological and potential specificity could be due to a succession of fungi in orchid tissues, but further investigations are necessary to confirm this hypothesis.

Our study was carried out in two steps: 1) isolation and description of Serapias parviflora endomycorrhizal fungi; 2) description of associations, in vitro, between S. parviflora and fungi, and between Spiranthes spiralis and fungi. S. parviflora was used as control and S. spiralis was used to verify the existence of specificity between host and endophyte.

Materials and methods. Serapias parviflora roots samples were collected at Allerona Scalo (Umbria, Italy) on 05/16/1999. The whole plant, together with a clump of soil, was collected, in order to prevent root damage. Samples were preserved in sterilised envelopes at $5^{\circ} \mathrm{C}$ until fungal isolation (two days after collection). To remove fungi and bacteria from external surfaces, roots were sterilised by immersion on $\mathrm{H}_{2} \mathrm{O}_{2} \quad(30 \%)$ for 4 minutes; then they were rinsed 4 times in sterile distilled water. Roots were cut, $1 \mathrm{~cm}$ segments were sowed on Petri dishes with PDA and streptomycin (a broad-spectrum antibiotic) and then incubated at $20^{\circ} \mathrm{C}$. Fungi were observed under phase contrast microscope, scanning and transmission electron microscope and confocal laser microscope. For the latter there is no need of a particular preparation but fungi stained better when coloured with acid fuchsin. Fungi observed under TEM were 


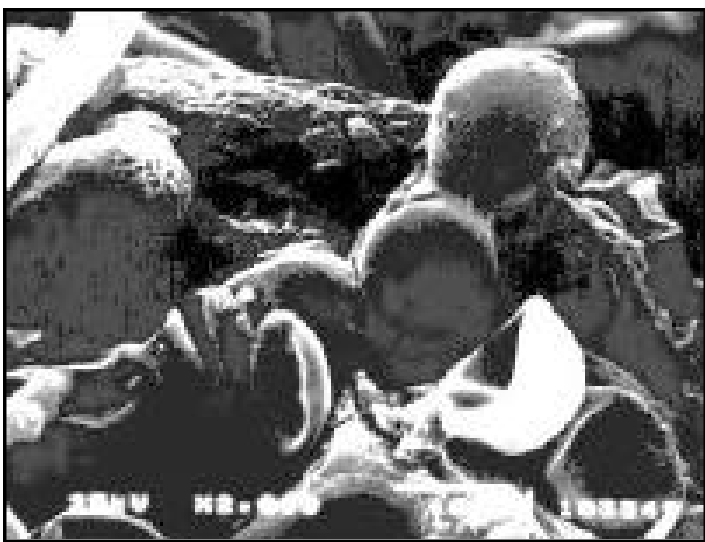

Figure 1. B-Sepa-1 monilioid cells (SEM, x 2000).

treated as follows: growth on liquid medium, fixation for 2 hours in para-formaldehyde/glutaraldehyde $(2 \% / 2.5 \% \mathrm{v} / \mathrm{v})$ in phosphate buffer $0,025 \mathrm{M}$ $\mathrm{pH} 7$ at $25^{\circ} \mathrm{C}$, rinsed 3 times in phosphate buffer $0,025 \mathrm{M}$, postfixation in OsO4 $1 \%$ in $0,05 \mathrm{M}$ phosphate buffer v/v for 12 hours at $4^{\circ} \mathrm{C}$, dehydration in a graded ethyl alcohol series for 15 minutes each $(10 \%, 30 \%, 50 \%, 75 \%)$ and for 1 hour in pure ethyl alcohol, embedding on Spurr's epoxy resin and polymerisation for 8 hours at $70^{\circ} \mathrm{C}$. Thin sections $(70 \mathrm{~nm})$, stained with uranil acetate, $10 \% \mathrm{v} / \mathrm{v}$ in $50 \%$ ethanol (v/v) for 7 minutes at $70^{\circ} \mathrm{C}$ and freshly prepared lead citrate $(1 \% \mathrm{v} / \mathrm{v}$ on $50 \%$ ethanol $\mathrm{v} / \mathrm{v}$ ) for 12 minutes at $25^{\circ} \mathrm{C}$ were observed.

Fungi were inoculated in $S$. parviflora plants to confirm symbiosis and in Spiranthes spiralis plants to establish specificity. All plants were asymbiotically grown from seeds (modified Frosch medium) and transplanted on medium for symbiotic growth (modified Basic Oats medium, Riess and Pacetti, 2001) before inoculation.

Results. Many fungi were isolated from roots of Serapias parviflora but only two strains had characters of symbiotic fungi: mycelium with septa, monilioid cells, sclerotia, without asexual spores (grown on PDA until substrate exhaustion). Two fungi were able to form, in vitro, typical pelotons in $S$. parviflora and Spiranthes spiralis root cortex cells. They were called B-Sepa-1 and A-Sepa-1.

B-Sepa-1 (PDA) produces floccose to velutinous colonies, without water-soluble pigments and substrate pigmentation. Mycelium superficial and

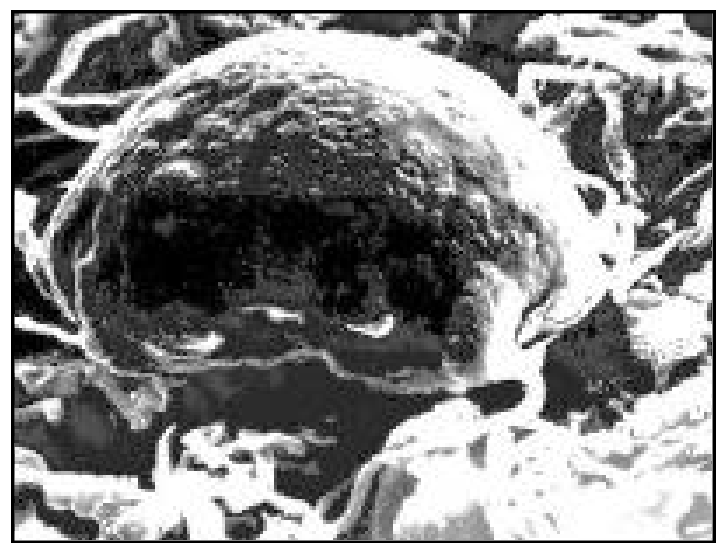

Figure 2. B-Sepa-1 sclerotium (SEM, x 1000).

from white to light grey. On PDA, monilioid cells (fig. 1) and sclerotia (fig. 2) are differentiated. Vegetative hyphae hyaline, septated, with constriction on branched point and with smooth wall (fig. 3 ). Thin wall and hyaline monilioid cells, from ellipsoidal to spherical, 4,5 x 6,5 mm, organised in septated chains and branched or linear chains (fig. 4). Sclerotia torulose, $120 \times 70 \mathrm{~mm}$. Dolipores always present under TEM (fig. 5).

A-Sepa-1 (PDA) consisting of floccose and from light yellow to yellow colonies with white to light grey micelium on peripheral area. Uncoloured exudate, from dark grey to black water-soluble pigments and monilioid cells are produced. Vegetative hyphae hyaline, septated, with smooth walls. Hyaline monilioid cells are differentiated. Spherical to irregular, 4,5-15 x 6,5-15 mm, organised in linear and never branched chains. Thick and irregular electron dense layer around hyphae (fig. 6), Woronin bodies near septum pore (fig. 7).

Symbiosis between S. parviflora and B-Sepa-1 was observed under microscope. In these associations there is a massif fungal penetration of roots, preferentially through hairs (fig. 8) but in some case there is epidermal penetrations too. Subepidermal invasion is confined to the first two cortex layers. Pelotons and digested pelotons can be observed from the third to the eighth cellular layer. In some sections we can find both pelotons (fig. 9) and digested pelotons (fig. 10) in the same cell. We can also assume an infective cyclical pattern by observing mycelium intercellular connections (fig. 11). 


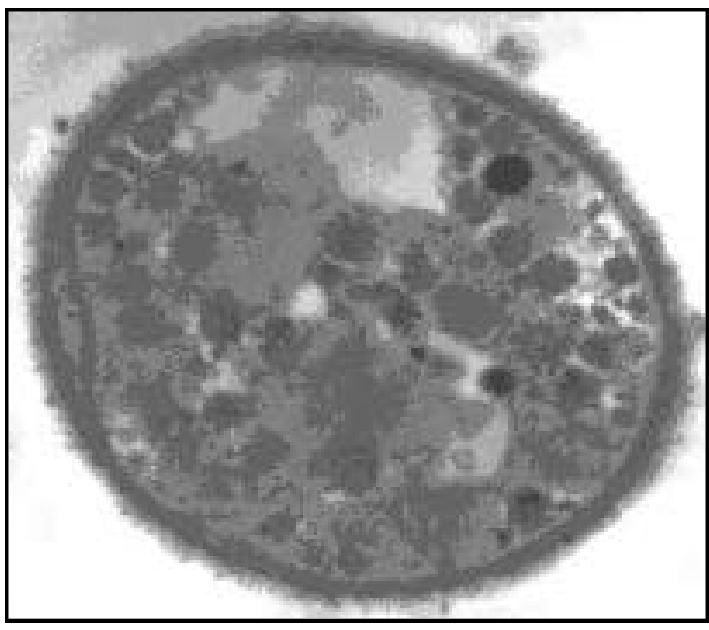

Figure 3. Trasversal section of B-Sepa-1 hypha (TEM, x 22500).

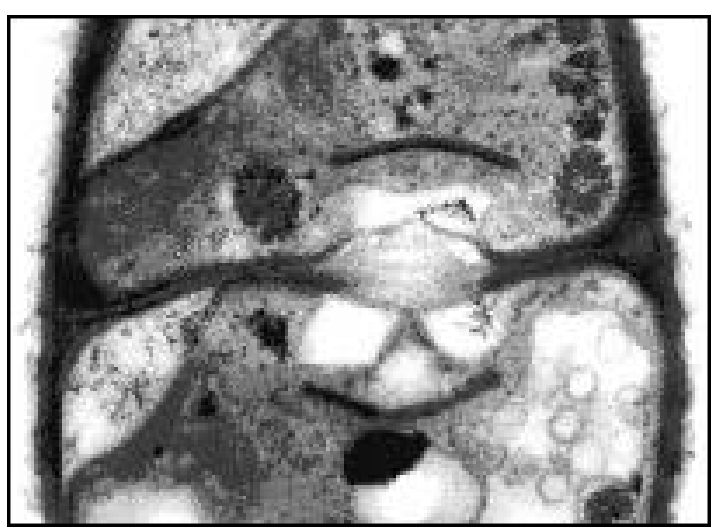

Figure 5. B-Sepa-1 septal ultrastructure with dolipore (TEM, x 45000).

In S. parviflora roots, inoculated with A-Sepa-1, there are few observations of epidermal penetrations (fig. 12). There is a slight subepidermal invasion and there are pelotons (fig. 13) and digested pelotons in the inner layers of the cortex (from the third to the sixth). Pelotons occupy a smaller cytoplasm portion compared to B-Sepa-1 in the same orchid.

As to S. spiralis inoculated with B-Sepa-1, it is possible to say that fungus preferentially penetrates through hairs (fig. 14), even if epidermal penetration is quite frequent (fig. 15). It is impossible to see subepidermal invasion because the first five layers are completely invaded by pelotons and digested pelotons (fig. 16 and 17). In this case,

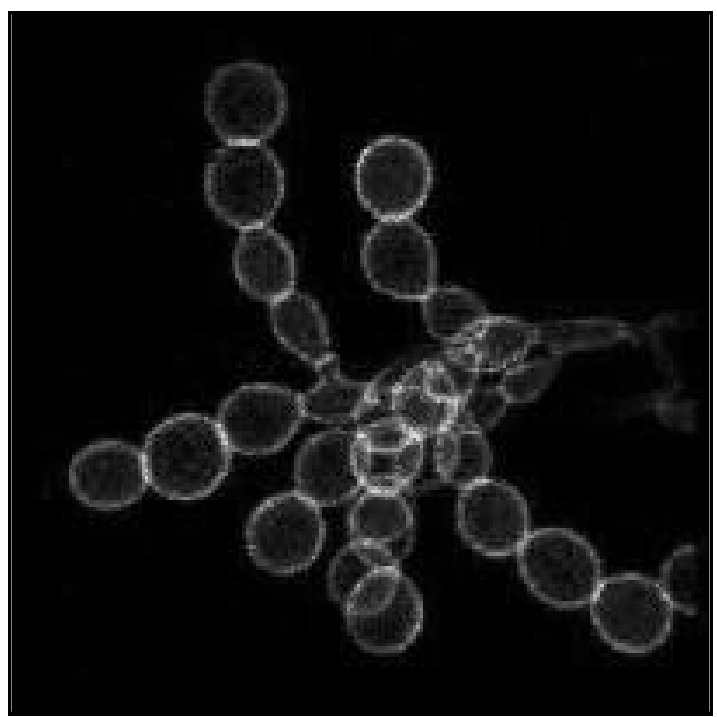

Figure 4. B-Sepa-1 monilioid cells (confocal laser microscope, x 80).

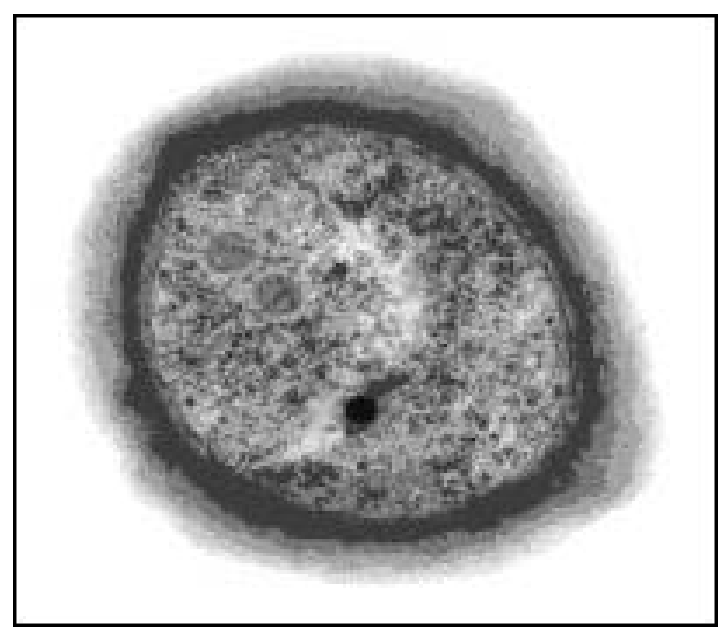

Figure 6. Trasversal section of A-Sepa-1 hypha, with a thick and irregular electron-dense layer sorrounding the cellular wall (TEM, x 30000).

intercellular micelium connections are very clear. Beyond the fifth cellular layer of the cortex there is no fungus but there are many starch granules (fig. 18).

In S. spiralis, inoculated with A-Sepa-1, there are only very few partially or completely digested pelotons. Epidermal invasion is the only means observed for fungal penetration; hairs root invasion is never observed.

Fungal hyphae diameters are quite constant both 


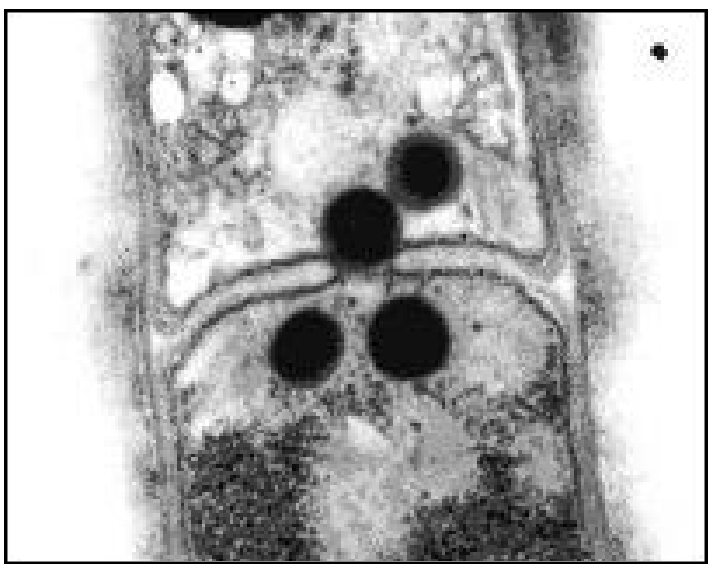

Figure 7. A-Sepa-1 septal ultrastructure, with Woronin bodies (TEM, x 45000).

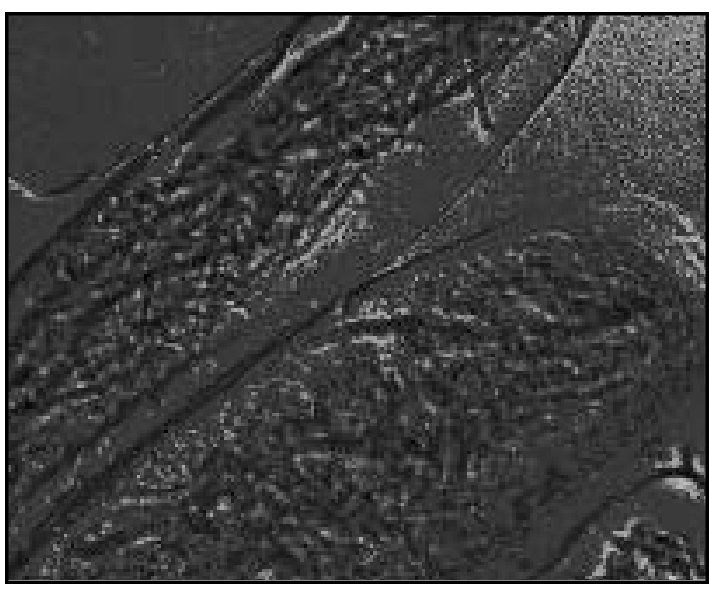

Figure 9. B-Sepa-1 pelotons in S. parviflora root cortex, stained by acid fuchsin (phase contrast microscope, $\mathrm{x}$ $40)$.

in pure cultures on PDA and in the hosts: in BSepa-1 diameters are on average $2 \mathrm{~mm}$, while in A-Sepa-1 diameters are on average $3,5 \mathrm{~mm}$.

Conclusion. Endophytes isolation from roots of Serapias parviflora reveals the presence of two fungi. Our technique allows us to determine only the division. A-Sepa-1 is an ascomycetes (presence of Woronin bodies), and B-Sepa-1 is a basidiomycetes (presence of dolipores). We can also recognise Riess and Scrugli morphometrical classes: A-Sepa-1 belongs to class B, with diameters of hyphae ranging from 2,6 to $5 \mathrm{~mm}$, while B-Sepa-1 belongs to class $\mathrm{A}$, having hyphae with diameters less than 2,5 mm. Molecular markers could certain-

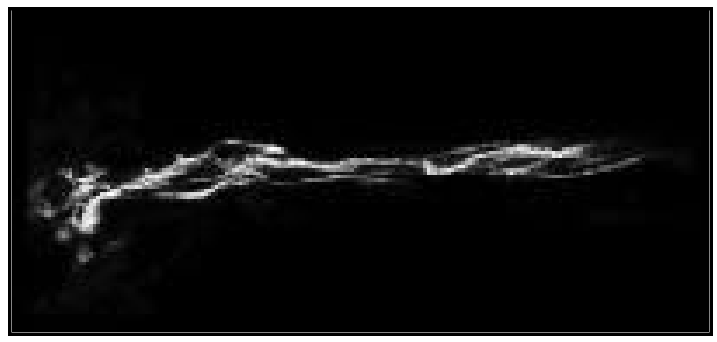

Figure 8. S. parviflora hair massively invaded by BSepa-1 (confocal laser microscope, $\mathrm{x} 40$ ).

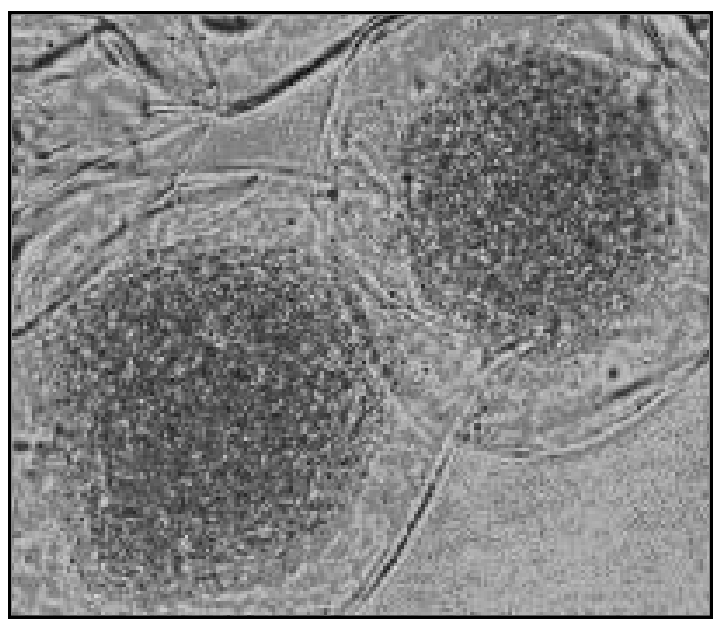

Figure 10. B-Sepa-1 partially digested pelotons in $S$. parviflora roots, stained by acid fuchsin (x 40 ).

ly provide diagnostic tools for lower taxonomical levels and taxon fingerprints. .

We can not tell if S. parviflora needs two fungi simultaneously or in succession for its development. Only observations of endophytes in samples living in the same site could maybe answer this question.

A-Sepa-1 and B-Sepa-1 behave differently when inoculated in plants of S. parviflora and Spiranthes spiralis: B-Sepa-1, the basidiomycetes, is a good symbiont for both orchids, i.e. it is always possible to see all typical mycorrhizal phases, their cyclical pattern and the absence of fungi in orchids root vascular tissue. A-Sepa-1, the ascomycetes, is a good symbiont only for S. parviflora; in this orchid we can observe fungal confinement in the first layer of root cortex, starch accumulation in the inner layers, cyclic infections and absence of fungus in vascular tissue. A-Sepa-1 is not tolerate by $S$. spi ralis: there is a massif epidermal penetration but 


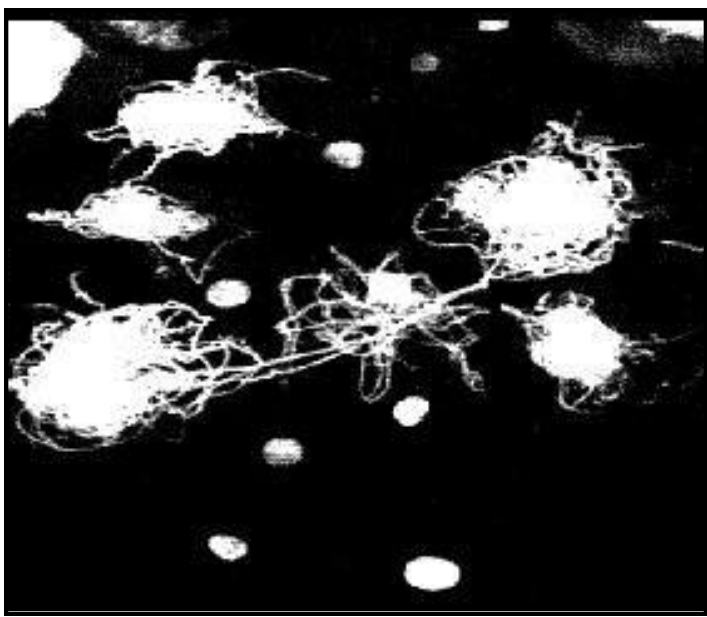

Figure 11. B-Sepa-1 pelotons with intercellular connections, stained by acid fuchsin (confocal laser microscope, $x$ 24).

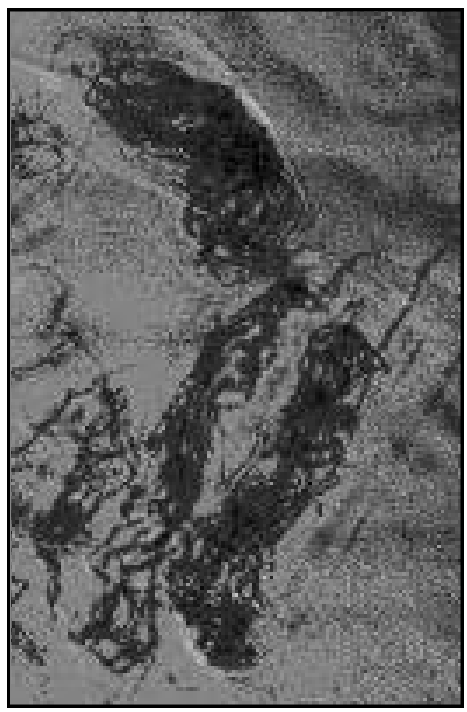

Figure 13. A-Sepa-1 pelotons in S. parviflora, stained by acid fuchsin (phase contrast microscope, x 20).

there is no penetration through hairs. The very few pelotons are digested immediately and mycelium can not invade the other cells: typical symbiotic alternation of infection and digestion seems to be shifted toward digestion.

Symbiosis between A-Sepa-1 and S. parviflora and digestion of fungus in S. spiralis suggest a different potential specificity of the fungus for the two

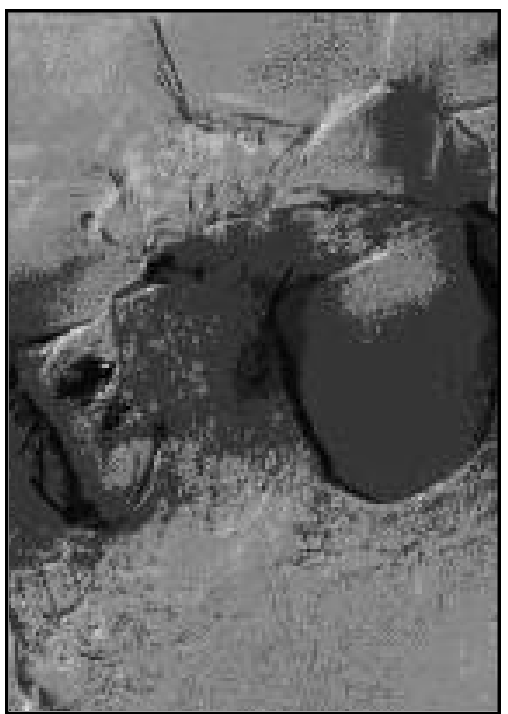

Figure 12. A-Sepa-1 epidermal penetration in S. parvi flora (phase contrast microscope, x 40).

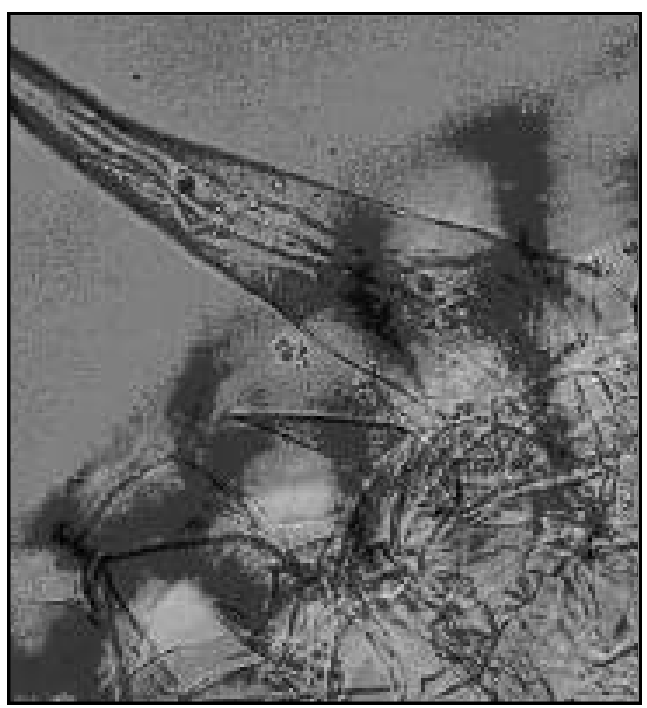

Figure 14. B-Sepa-1 penetration in S. spiralis root by hair (x 40).

hosts: S. parviflora is micorrhizated by the two fungi and $S$. spiralis only by B-Sepa-1, in vitro. If it is true, inoculation of fungi in S. parviflora and $S$. spiralis and their infective patterns are an additional confirmation that there is no species-specificity, but potential or ecological specificity between orchids and fungi, as suggested from Masuhara and Katsuya (1989). 


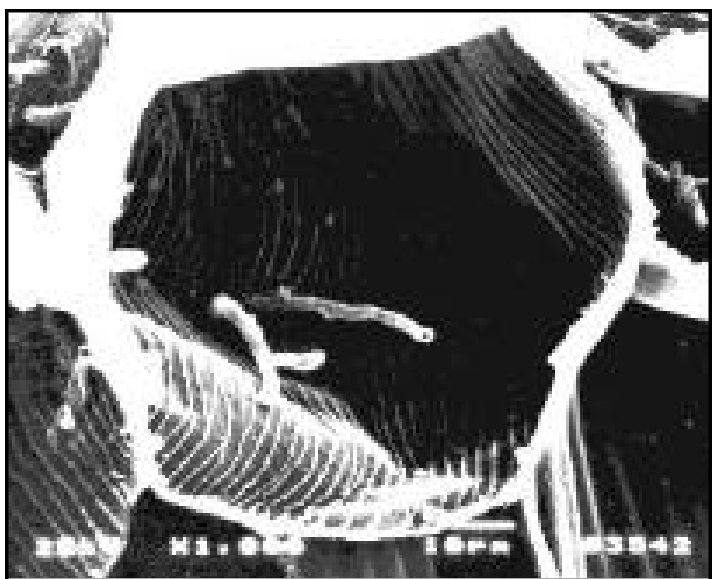

Figure 15. S. spiralis epidermal root cell penetrated by B-Sepa-1 (SEM, x 1,000).

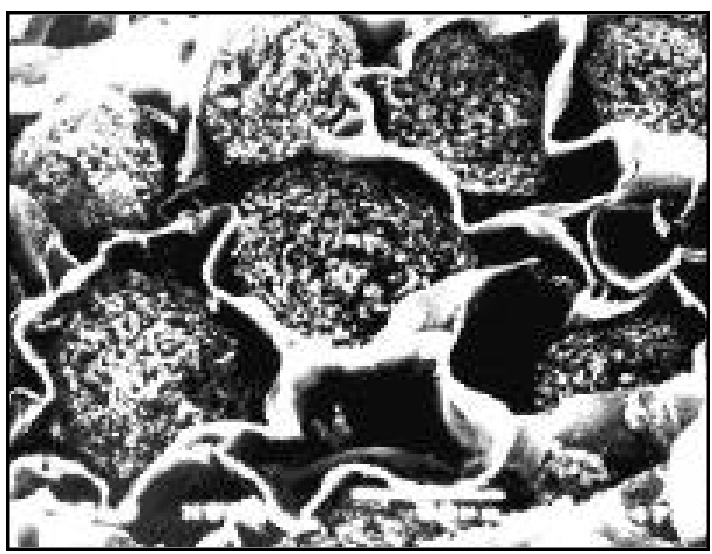

Figure 17. B-Sepa-1 pelotons in a S. spiralis root section (SEM, x 500).

The different pattern of infection of the two fungi in $S$. spiralis could also suggest that there is a fungal succession in this host, and that A-Sepa-1 can not induce symbiosis in $S$. spiralis in the phase of development studied.

\section{LiterATURE Cited}

Andersen, T. F. 1996. A comparative taxonomic study of Rhizoctonia sensu lato employing morphological, ultrastructural and molecular methods. Mycol. Res. 100: 1117-1128.

Bernard, N. 1909. L'evolution dans la symbiose. Ann. Sci. Nat. Bot. 9, ser. 9: 1-196.

Burgeff, H. 1936. Samenkeimung der Orchideen. G. Fischer, Jena.

Curtis, J.T. 1937. The relation of specificity of Orchid

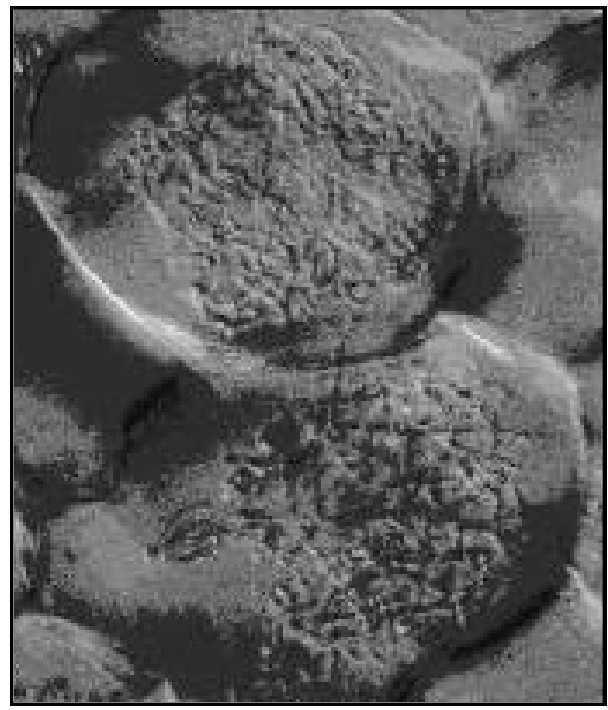

Figure 16. B-Sepa-1 pelotons in S. spiralis root cells (confocal laser microscope, $\mathrm{x} 40$ ).

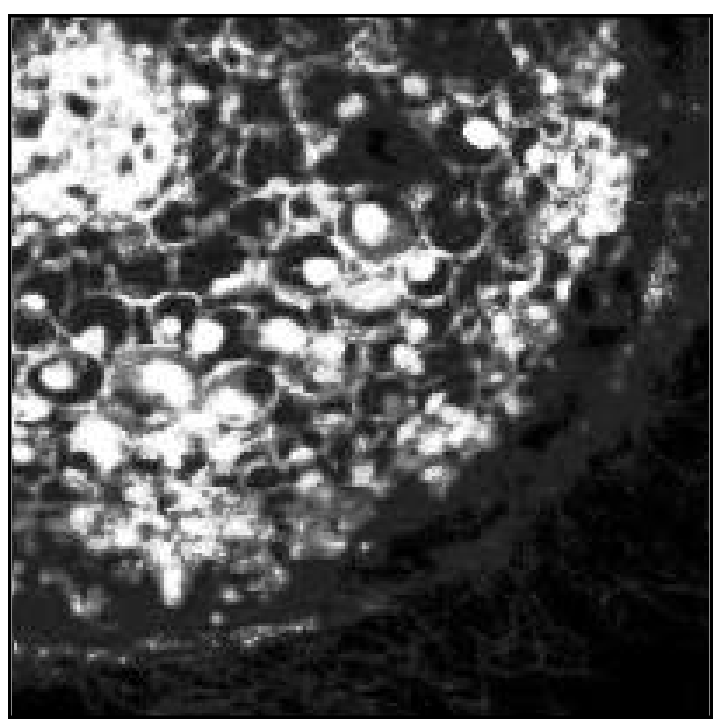

Figure 18. S. spiralis root section with B-Sepa-1 invasion area (confocal laser microscope).

mycorrhizal fungi to the problem of symbiosis. Amer. J. Bot. 26: 390-398.

Downie, D.G. 1943. Notes on the germination of Corallorhiza innata. Trans. Bot. Soc. Edinburgh 33: 380-392.

1959. The mycorrhiza of Orchis purpurella. Trans.

Bot. Soc. Edinburgh 38: 16-29.

Dreyfuss, M. \& O. Petrini. 1981. Endophytische Pilze in Epiphytischen Araceae, Bromeliaceae und Orchidaceae. Sydowia 34: 135-148. 
1984. Further investigations on the occurrence and distribution of endophytic fungi in tropical plants. Bot. Helvetica 94: 33-40.

Hadley, G. 1970. Non specificity of symbiotic infection in orchid micorrhiza. New Phytol. 69: 1015-1023.

Hadley G. \& G. Harvais. 1967. The relation between host and endophyte in orchid micorrhiza. New Phytol. 66: 205-215.

Harley, J.L. 1969. The biology of micorrhiza. 2nd ed., Leonard Hill Books, London.

Masuhara, G. \& K. Katsuya. 1989. Effects of mycorrhizal fungi on seed germination and early growth of three japanese terrestrial orchids. Sci. Hort. 37 : 331-337.

Masuhara, G., K. Katsuya \& K. Yamaguchi. 1993. Potential for symbiosis of Rhizoctonia solani and binucleate Rhizoctonia with seeds of Spiranthes sinensis var. amoena (Orchidaceae) in vitro. Mycol. Res. 97: 746-752.

Masuhara, G. \& K. Katsuya. 1994. In situ and in vitro specificity between Rhizoctonia spp. and Spiranthes sinensis (Persoon) Ames. var. amoena (M. Bieberstein) Hara (Orchidaceae). New Phytol. 127: 711-718.
Masuhara, G., P.A. McGee \& A.J. Perkins. 1995. Specificity of the associations between Microtis parvi flora (Orchidaceae) and its mycorrhizal fungi. Austral. J. Bot. 43: 85-91.

Rambelli A. 1981. Fondamenti di micologia. Edizioni Zanichelli, Bologna.

Riess, S. \& A. Scrugli. 1987. Associazioni micorriziche nelle orchidee spontanee della Sardegna. Micol. Ital. XVI (3): 21-28.

Riess, S, A. Cogoni \& A. Scrugli. 1992. Rilevamenti morfometrici sugli endofiti di 38 Orchidaceae spontanee della Sardegna. Micol. Ital. XXI (2): 21-28.

Riess, S. \& P.L. Pacetti. 2001. Germinazione e sviluppo in vitro, simbiotico ed asimbiotico, di alcune specie di orchidee spontanee italiane. Caesiana 15: 25-32.

Talbot, P.H.B. \& J.H. Warcup. 1967. Perfect states of Rhizoctonias associated whith Orchids. New Phytol. 66: 631-641.

Warcup, J.H. 1975. Factors affecting symbiotic germination of orchid seed. In Sanders F.E., Mosse B., Tinker, P.B (eds.). Endomycorrhiza, p. 85-104. London. 